\section{THE RAPIDITY OF DETONATION}

A CIRCUMSTANCE of singular interest has recently $A$ been revealed in connection with the investigations still being carried on with gun-cotton at Woolwich Arsenal. The experiments made with this powerful explosive have now extended over a period of ten years, and although many discoveries of vital interest have been made by Professor Abel and by Mr. E. O. Brown, who is aiding in the research, the results teach us, before everything, how much more we have yet to learn of the properties of pyroxilin. First of all, the violence of its explosion had to be tamed, then a compressed form of the material was devised, and after that it was shown that, like its sister-explosive, nitro-glycerine, gun-cotton could be violently detonated, if ignited by a charge of fulminate. Gun-cotton, in fact, turns out to be sympathetic, for, according to the energy with which it is inflamed, so it responds in its behaviour: thus, if gently ignited by a spark, the cotton, in the form of yarn, smouldered slowly away; when set fire to by a flame, it burnt up rapidly; if in the form of a charge it was exploded in a mine or a fire-arm, it at once resented the shock and replied with corresponding energy, behaving like gun. powder under similar circumstances; while, lastly, if fired with great violence with a few grains of fulminate, it is detonated with as much force and with the same terrible effect as its instigator.

More recently, as many may have heard, our investigators have succeeded in detonating, or, in other words, exploding to the best advantage, gun-cotton when in a damp condition; and in this state the explosion is cvery bit as violent as when the material is dry. This grand discovery is naturally of the utmost importance, because, although many objections may be advanced as to the danger of storing and using gun-cotton when dry, the most nervous of us would scarcely hesitate to employ it sopping wet. In this latter condition the material is, strange to say, not only non-explosive, but positively noninflammable; so much so, indeed, that it would be probably as serviceable in putting out a fire as a wet blanket or a damp towel would be. It can neither be inflamed nor exploded when wet; and further, unless one has the key to its detonation-a little fulminate of mercuryit is of no more value as an explosive than so much wet paper pulp. When placed in contact, however, with a fuse of the proper construction and a cake of dry guncotton, to start the action, the wet pyroxiline, as we have said before, detonates as readily as when the moisture amounts to but a fraction of a per cent. Moreover, the quantity of water in the material is really of no importance, for it has been found that for submarine mines, compressed cakes cnclosed in a fishing-net and thrown overboard with a dry primer and a fulminate fuse, will explode with just as much energy as when confined in a water-tight steel case.

It is in respect to this detonation, and more particularly to the rapidity of its action, that we desire to speak at the present moment. Recent experiment has shown that the rapidity with which gun-cotton detonates is altogether unprecedented, the swiftness of the action being truly marvellous. Indeed, with the exception of light and electricity, the detonation of gun-cotton travels faster than anything else we are cognizant of. Thus, detonation will run along a line of gun-cotton cakes, placed so as to touch one another. with a rapidity only inferior to that of electricity, setting fire to a charge or conveying a signal, if desired, almost instantaneously. Twenty thousand feet, or nearly three miles per second, is calculated to be its rate of travelling according to Noble's electric chronoscope. In one experiment forty-two feet of the material was fired, and records secured at every six feet; and in this case the results given were most uniform, for the velocity only varied frem nineteen to twenty thousand feet per second, the ratio of transit being in no instance less than this.
To form an approximate idea of this extraordinary rapidity, it is necessary to call to mind the rates of travelling of other mediums. Light and electricity we may leave out of the question, as these are immaterial bodies. A bullet usually flies at the rate of 1,300 feet per second, although rifled barrels have been known to project a shot with a velocity of $I, 400$ feet. Sound is much slower in travelling, for a second of time is required in getting through some $I, 100$ feet. A quick match of the most delicate construction would probably be longer still in making way, and a train of gunpowder would be left far behind. So it may be safely affirmed, we think, that the detonation of gun-cotton travels more rapidly than any other known medium, with the exception, we repeat, of light and electricity.

It is curious to note that not every detonating or fulminating substance will induce the detonation of gun-cotton. It seems as if a certain number of vibrations require to be set up-a certain key-note to be struck-in order to secure the decomposition of the material. Thus it is found that fulminate of mercury detonates guncotton readily, while again it is also capable of being detonated by itself; so that if a line of compressed cakes is detonated at one end by a charge of fulminate of mercury, the detonation is communicated rapidly from one cake to another, until they are all consumed. Nor does the force diminish at all as it runs along the line, as might perhaps be imagined; if this were the case, the detonation set up at the beginning of a line would only run up to a certain distance, and there come to a full stop, as soon, that is, as the vibrations are insufficient to explode the gun-cotton. This, however, does not happen in actual experiment; and, on reflection, it stands to reason that if the first cake of pyroxilin is capable of firing the second one, the ninety-ninth is just as ready to detonate the hundredth. Thus the detonation can be carried along a line of any length, and the force is as powerful and violent at the end as it was at the beginning.

This property of gun-cotton may obviously be put to valuable use both in industrial and military operations. In any case where it is of importance that a series of blasting or mining charges should be fired simultancously, their connection together by means of gun-cotton would ensure such a result. True, the same effect could be obtained by means of an arrangement of insulated wires, the charges being detonated simultaneously with the aid of a battery, but such a plan is not always convenient nor practicable. For cutting down palisades, or stout wooden walls, a line of gun-cotton discs exploded in this way would be most efficacious; and a more ready plan of felling timber does not probably exist than that of placing
around the stem of a tree a chain or necklace of the explosive in the form of compressed cakes, the detonation of these dividing the trunk as sharply as the keenest axe.

\section{NOTES}

WE read in the Daily Newus:-"Mr. Ienry Cole, C. B., presided at the annual meeting of the Hanley School of Art, on Monday evening, and after speaking of the results of the South Kensington Museum, said it was his painful duty to announce that this organisation, whicls had borne such great fruits, and which was so highly prized by the nation, and was so indispen. sable to the commercial and social progress of this country, was in jeopardy. The Government contemplated changes which were directly opposed to the further development of the Science and Art Department. It had hitherto flourished under a management which ensured individual Parliamentary responsibility, but it was now proposed to hand over South Kensington to the Trustees of the British Museum, who were already fully occupied in their own departments. The management of the British Mfuseum was not such as to make them desirous of seeing 